\title{
Uso de Marcadores RAPD na Classificação de Isolados de Phytophthora spp. Causadores da Podridão Parda do Cacaueiro no Brasil
}

\author{
Fábio G. Faleiro ${ }^{* * 1,3}$, Edna Dora M.N. Luz ${ }^{* * * 2}$, Ademildes O. Cerqueira ${ }^{2}$ \& Cenilda S.S. Rocha ${ }^{2}$ \\ ${ }^{1}$ Laboratório de Biotecnologia, Seção de Genética, ${ }^{2}$ Seção de Fitopatologia, CEPEC/CEPLAC, Cx. Postal 07, CEP 45600-000, \\ Itabuna, BA; ${ }^{3}$ Embrapa Cerrados, Cx. Postal 08223, CEP 73301-970, Planaltina, DF, e-mail: ffaleiro@ cpac.embrapa.br
}

(Aceito para publicação em 04/12/2002)

Autor para correspondência: Fabio G. Faleiro

FALEIRO, F.G., LUZ, E.D.M.N., CERQUEIRA, A.O. \& ROCHA, C.S.S. Uso de marcadores RAPD na classificação de isolados de Phytophthora spp. causadores da podridão parda do cacaueiro no Brasil. Fitopatologia Brasileira 28:312-315. 2003.

\section{RESUMO}

Objetivou-se neste trabalho propor uma metodologia para a utilização de marcadores RAPD como uma ferramenta auxiliar na classificação de isolados de Phytophthora spp. causadores da podridão-parda do cacaueiro (Theobroma cacao) no Brasil. Existe uma necessidade constante de monitorar populações de Phytophthora spp. nas regiões cacaueiras do Brasil e a tarefa de classificação dos isolados é difícil e demorada. Com base em estudos de diversidade genética de isolados de Phytophthora capsici, $P$. palmivora e $P$. citrophthora por meio de marcadores RAPD, foram escolhidos três isolados de cada espécie como padrões e dois "primers" decâmeros mais informativos na diferenciação das espécies (OPA 13 e OPH 18). O DNA genômico dos isolados padrões e de três isolados não classificados foi extraído e amplificado, utilizando-se os dois "primers" decâmeros mais informativos. Os padrões de marcadores RAPD obtidos permitiram uma diferenciação visual clara dos isolados de cada espécie e mostraram-se úteis na classificação de isolados de Phytophthora spp. A metodologia proposta já está sendo utilizada no Centro de Pesquisas do Cacau, solucionando eventuais dúvidas resultantes da caracterização morfológica dos isolados.

Palavras-chave adicionais: Phytophthora capsici, $P$. palmivora, P. citrophthora e Theobroma cacao.

\section{ABSTRACT}

Use of RAPD markers for the classification of Phytophthora spp. isolates causing cacao black pod disease in Brazil

This work proposes the use of RAPD markers as an auxiliary tool for the classification of Phytophthora spp. isolates, causal agents of black pod, an important disease of cacao (Theobroma cacao) in Brazil. The monitoring of Phytophthora spp. populations in the cacao growing areas of Brazil requires constant identification of isolates, which is a time consuming task. Based on genetic diversity studies of isolates of $P$. capsici, P. Citrophthora, and P. palmivora using RAPD markers, three standard isolates of each species were selected.
The two most informative decamer-primers for differentiation of species (OPA 13 and OPH 18) were also selected. The genomic DNA of the three standard isolates of each species and of three unknown isolates were extracted and amplified using the selected decamer-primers. The RAPD markers obtained allowed the differentiation of isolates of each species and were a useful auxiliary tool for the classification of Phytophthora spp. isolates. The methodology proposed has been used at the Cocoa Research Center, solving eventual doubts resulting from the morphological characterization of isolates.
A podridão-parda ou podridão-de-Phytophthora é a principal doença do cacaueiro (Theobroma cacao L.), considerando a sua ocorrência em todos os países produtores. No Brasil, em condições favoráveis ao desenvolvimento da doença, esta pode causar perdas na produção de até $80 \%$ (Luz et al., 1997). Phytophthora capsici Leonian, segundo levantamentos realizados entre 1977 e 1981, é a espécie predominante na Bahia e no Espírito Santo (Campêlo \& Luz, 1981). Entretanto, levantamentos posteriores mostraram tendência de crescimento das populações de Phytophthora palmivora (Butl.) Butler e P. citrophthora (Smith and Smith) Leonian, especialmente nas áreas foco da doença no Estado

\footnotetext{
* Auxílio financeiro: CFC/ICCO/CEPLAC-BIOMOL e FUNDECAU

** Bolsista do IBECAU

****Bolsista do CNPq
}

da Bahia (Luz et al., 1997). A espécie Phytophthora hevea Thompson também foi relatada na Bahia, mas é considerada como de patogenicidade moderada ao cacaueiro. Considerando-se diferentes aspectos relacionados ao controle da doença, o monitoramento das populações de Phytophthora spp. nas regiões cacaueiras do Brasil é de extrema importância e precisa ser feita constantemente.

Para o monitoramento de populações de fitopatógenos, a existência de caracteres ou marcadores precisos e de fácil detecção são essenciais. A taxonomia e identificação de espécies de fungos fitopatogênicos é usualmente baseada em caracteres morfológicos. Em muitos gêneros, incluindo Phytophthora, tais caracteres são de difícil observação em populações naturais, além de, muitas vezes, serem afetados pelo ambiente. Muitos caracteres morfológicos são também 
comuns entre diferentes espécies e sofrem modificações de acordo com o meio de cultura, idade das colônias, condições de incubação, entre outros fatores, o que pode trazer problemas para a correta identificação e classificação de isolados (Erwin, 1983; Waterhouse et al., 1983; Cerqueira et al., 1999).

Espécies fitopatogênicas do gênero Phytophthora apresentam alta variabilidade inter e intra-específica, tornando a classificação das mesmas uma tarefa difícil (Cerqueira et al., 1999). Diversos critérios têm sido adotados na sistemática do gênero, predominando as características morfológicas e biométricas preconizadas pelas chaves de Waterhouse (1963), Newhook et al. (1978) e Stamps et al. (1990). Muitas vezes, tais características são insuficientes para a classificação, sendo necessário o uso de marcadores genéticos adicionais como aqueles obtidos por eletroforese de proteínas totais, isoenzimas, polimorfismos de DNA e RNA, análise de cariótipo, serologia e antígenos (Luz \& Matsuoka, 1996).

Marcadores genéticos baseados em polimorfismos do DNA têm sido utilizados com sucesso na diferenciação de espécies do gênero Phytophthora (Panabieres et al.,1989; Goodwin et al., 1989; Crawford et al., 1996; Cooke \& Duncan, 1997; Sackey et al., 1999). Entre as vantagens destes marcadores estão a menor ambigüidade, a detecção rápida e precisa, a confiabilidade e o fato de não serem influenciados pelas condições ambientais (Goodwin et al., 1989).

Nesse trabalho, propõe-se uma metodologia para a utilização de marcadores RAPD (Random Amplified Polymorphic DNA) na classificação de isolados de Phytophthora spp. causadores da podridão-parda do cacaueiro no Brasil. A metodologia proposta está fundamentada no trabalho realizado por Cerqueira et al. (2002) que utilizaram marcadores RAPD para analisar a diversidade genética de 22 isolados de $P$. capsici, $P$. palmivora e $P$. citrophthora. Neste trabalho, foram utilizados sete "primers" decâmeros que geraram 191 marcadores RAPD, os quais permitiram diferenciar os isolados de cada espécie. A partir da análise dos dados deste trabalho foram escolhidos os dois "primers" mais informativos e com padrão de bandas mais nítido e reprodutível. Também foram selecionados três isolados de cada espécie do gênero Phytophthora para serem utilizados como padrões.

Massa micelial de cada um dos isolados padrões e de mais três isolados de cada espécie foi produzida em placas de Petri contendo o meio batata-dextrose líquido. O DNA genômico de cada isolado foi extraído a partir de, aproximadamente, $250 \mathrm{mg}$ de massa micelial, utilizando-se o método do SDS com algumas modificações: o micélio foi macerado em cadinho de porcelana em contato com $\mathrm{N}_{2}$ líquido. Em seguida, o macerado foi colocado em um tubo plástico de 1,5 $\mathrm{ml}$, ao qual foram adicionados $700 \mu \mathrm{l}$ de tampão de lise constituído por Tris- $\mathrm{HCl} 200 \mathrm{mM}$, pH 8,0, EDTA $25 \mathrm{mM}$, dodecil sulfato de sódio $1 \%, \mathrm{NaCl} 250 \mathrm{mM}$ e 2-mercaptoetanol 1\%. O macerado foi misturado ao tampão de lise e os tubos mantidos em banho-maria $\left(70^{\circ} \mathrm{C}\right)$ por $1 \mathrm{~h}$, sendo agitados, a cada $10 \mathrm{~min}$. Após a incubação, foi realizada a desproteinização, adicionando-se $600 \mu \mathrm{l}$ de clorofórmio-álcool isoamílico (24:1 v/v). Em seguida, as amostras foram agitadas, por suaves inversões, por 10 min e centrifugadas a $4{ }^{\circ} \mathrm{C}$, a $18845 \mathrm{~g}$, por $10 \mathrm{~min}$. O sobrenadante de cada amostra foi transferido para tubos de $1,5 \mathrm{ml}$ limpos e o processo de desproteinização foi repetido.

Para a precipitação do DNA, foi adicionado ao sobrenadante final $1 / 10$ do seu volume de acetato de sódio $3 \mathrm{M}, \mathrm{pH} 5,2$ e $2 / 3$ de isopropanol gelado. Os tubos foram mantidos a $-20{ }^{\circ} \mathrm{C}$ por $2 \mathrm{~h}$ e, a seguir, centrifugados como anteriormente. $\mathrm{O}$ sobrenadante foi descartado e o precipitado lavado duas vezes com etanol $70 \%$ (v/v) e seco à temperatura ambiente. Posteriormente, os ácidos nucléicos totais foram ressuspendidos em $150 \mu \mathrm{l}$ de água contendo RNAse na concentração de $40 \mu \mathrm{g} / \mathrm{ml}$ e colocados em banho-maria a 37 ${ }^{\circ} \mathrm{C}$ para a completa ressuspensão. Após esse período, o DNA foi novamente precipitado, centrifugado e ressuspendido em $100 \mu \mathrm{l}$ de água, como já descrito.

A quantidade do DNA foi estimada por espectrofotometria a $260 \mathrm{~nm}$ e a relação $\mathrm{A}_{260} / \mathrm{A}_{280}$ foi utilizada para avaliar a pureza do DNA. Bandas de DNA genômico total, separadas por eletroforese em gel de agarose $0,8 \%$, foram usadas como indicadoras da integridade do DNA extraído. Após esse processo, as amostras de DNA foram diluídas para $10 \mathrm{ng} / \mu \mathrm{l}$.

Amostras de DNA de cada isolado foram amplificadas pela técnica de RAPD. As reações de amplificação foram feitas em um volume total de $25 \mu \mathrm{l}$, contendo Tris- $\mathrm{HCl} 10 \mathrm{mM}$ (pH $8,3), \mathrm{KCl} 50 \mathrm{mM}, \mathrm{MgCl}_{2} 2 \mathrm{mM}, 100 \mu \mathrm{M}$ de cada um dos desoxinucleotídios (dATP, dTTP, dGTP e dCTP), 0,4 $\mu \mathrm{M}$ de um "primer" (Operon Technologies Inc., Alameda, CA, EUA), uma unidade da enzima Taq polimerase e, aproximadamente, $30 \mathrm{ng}$ de DNA. Os "primers" decâmeros OPH-18, OPA-13, OPI-12, OPA-19, OPE-19, OPE-14 e OPH-20, selecionados e utilizados por Cerqueira et al. (2002), foram reutilizados neste trabalho para obtenção dos marcadores RAPD. As amplificações foram efetuadas em termociclador, programado para 40 ciclos, constituídos pela seguinte sequiência: $15 \mathrm{~s} \mathrm{a} 94^{\circ} \mathrm{C}, 30 \mathrm{~s}$ a $35^{\circ} \mathrm{C}$ e $90 \mathrm{~s}$ a $72^{\circ} \mathrm{C}$. Após os 40 ciclos, foi feita uma etapa de extensão final de 7 min a $72^{\circ} \mathrm{C} \mathrm{e}$ finalmente, a temperatura foi reduzida para $4{ }^{\circ} \mathrm{C}$. Após a amplificação, foram adicionados, a cada amostra, $3 \mu 1$ de uma mistura de azul de bromofenol 0,25\% e glicerol $60 \%$ em água. Essas amostras foram aplicadas em gel de agarose $(1,2 \%)$, submerso em tampão TBE (Tris-Borato 90 mM, EDTA $1 \mathrm{mM}$ ). A separação eletroforética foi de, aproximadamente, 4 h, a 90 volts. Ao término da corrida, os géis foram corados com brometo de etídio e fotografados sob luz ultravioleta. Por fim, o padrão de amplificação gerado com a utilização de cada "primer" decâmero foi analisado.

Verificou-se que os padrões de amplificação gerados pelos "primers" decâmeros OPA13 e OPH18 foram os mais informativos, apresentando bandas nítidas e reprodutíveis. A utilização de apenas um desses "primers" já seria suficiente para a diferenciação dos isolados de cada espécie de Phytophthora (Figura 1). Os dois "primers" permitiram uma diferenciação visual clara dos isolados de $P$. capsici, $P$. 
palmivora e $P$. citrophthora. Isolados de $P$. megakarya e $P$. palmivora também puderam ser diferenciados com marcadores RAPD (Sackey et al., 1999). Diferenciações entre outras espécies do gênero Phytophthora com base em polimorfismos do DNA também são relatadas por outros autores (Crawford $e t$ al., 1996; Cooke \& Duncan, 1997).

O padrão de bandas permitiu a associação de isolados de classificação desconhecida aos isolados padrões (Figura 1). Esta associação foi possível devido a grandes diferenças inter-específicas dos isolados. Diferenças intra-específicas também podem ser verificadas pelas bandas polimórficas de

\section{A}

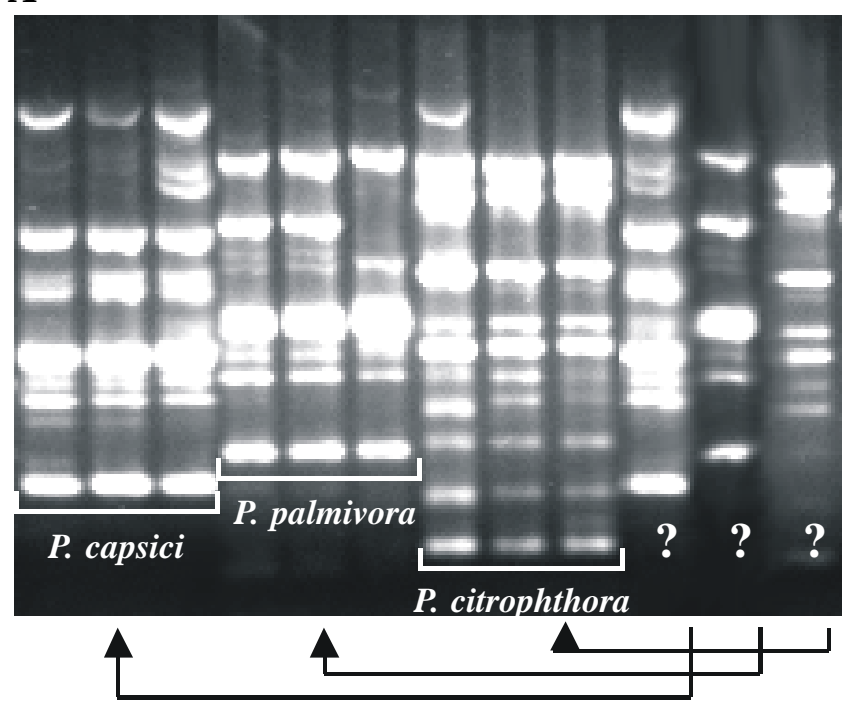

B

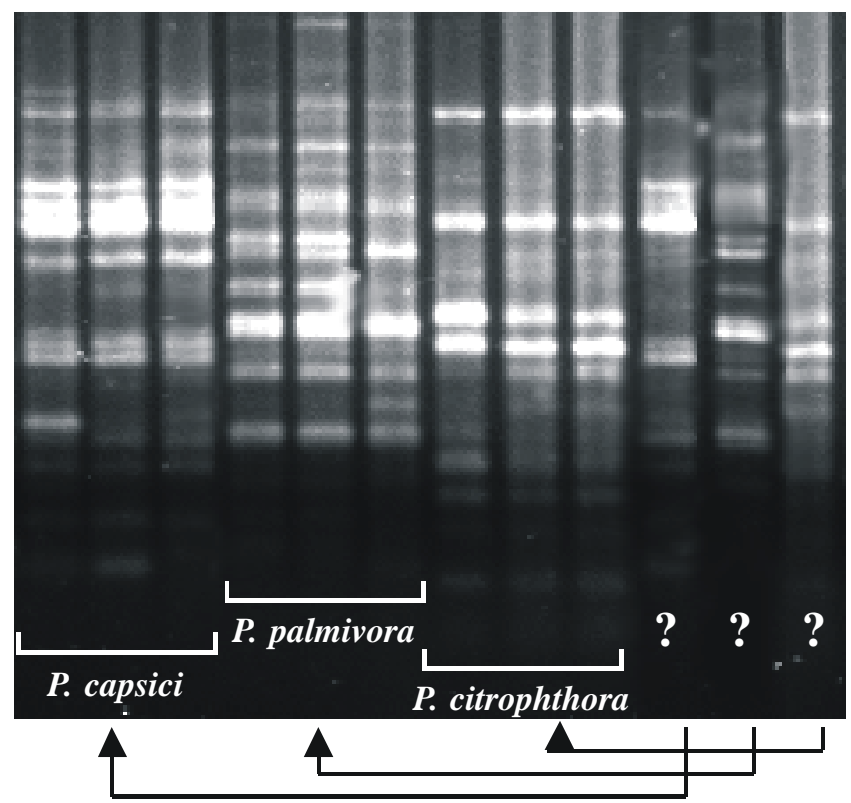

FIG.1 - Produtos de amplificação de DNA genômico de três isolados de Phytophthora capsici (1-3), três isolados de P. palmivora (4-6), três isolados de $P$. citrophthora (7-9) e três isolados de espécie desconhecida (10-12). A amplificação foi realizada utilizando-se o "primer" decâmero OPA-13 (A) e OPH-18 (B) para obtenção de marcadores RAPD.
DNA entre isolados da mesma espécie (Figura 1). Cerqueira $e t$ al. (2002) mostraram que as diferenças inter-específicas são muito maiores que as diferenças intra-específicas o que permite a diferenciação clara dos isolados de cada espécie do gênero Phytophthora com base nos marcadores RAPD.

Estudos morfológicos complementares realizados com os três isolados de classificação desconhecida em meios de cenoura-agar e caldo de cenoura comprovaram a classificação obtida com os marcadores RAPD. Tais estudos foram baseados na forma, caducidade dos esporângios, tamanho do pedicelo e presença/ausência de clamidósporos.

A metodologia proposta neste trabalho de utilização de marcadores RAPD para a diferenciação de isolados de Phytophthora spp. vêm sendo utilizada no Centro de Pesquisas do Cacau como uma ferramenta auxiliar na classificação dos isolados, solucionando eventuais dúvidas na interpretação de diferenças e similaridades morfológicas dos isolados.

\section{REFERÊNCIAS BIBLIOGRÁFICAS}

CAMPÊLO, A.M.F.L. \& LUZ, E.D.M.N. Etiologia da podridão parda do cacaueiro nos Estados da Bahia e Espírito Santo, Brasil. Fitopatologia Brasileira 6:313-321. 1981.

CERQUEIRA, A.O., LUZ, E.D.M.N. \& ROCHA, C.S.S. Caracterização morfológica e biométrica de alguns isolados de Phytophthora spp. da micoteca do Centro de Pesquisas do Cacau. Fitopatologia Brasileira 24:114-119. 1999.

COOKE, D.E.L. \& DUNCAN, M.J. Phylogenetic analysis of Phytophthora species based on ITS1 and ITS2 sequences of robosomal RNA gene repeat. Mycological Research 101:667-677. 1997.

CRAWFORD, A.R., BASSAM, B.J., DRENTH, A., MACLEAN, D.J. \& IRWIN, J.A. Evolutionary relationships among Phytophthora species deduced from rDNA sequence analysis. Mycological Research 100:437-443. 1996.

ERWIN, D.C. Variability within and among species of Phytophthora. In: Erwin, D.C., Bartnic-Garcia, S. \& Tsao P.H. (Eds.) Phytophthora, its biology, taxonomy, ecology and pathology. St. Paul, Minnesota, American Phytopathological Society. 1983. pp.149-165.

CERQUEIRA, A.O., FALEIRO, F.G., LUZ, E.D.M.N., ROCHA, C.S.S, DANTAS NETO, A., FLORES, A.B., BAHIA, R.C.S., FALEIRO, A.S.G. Diversidade genética de Phytophthora capsici, $P$. palmivora e $P$. citrophthora isoladas do cacaueiro com base em marcadores RAPD. Fitopatologia Brasileira 27:S94. 2002. (Resumo). GOODWIN P.H., KIRKPATRICK, B.C. \& DUNIWAY, J.M. Cloned DNA probes for the identification of Phytophthora parasitica. Phytopathology 79:716-721. 1989.

LUZ, E.D.M.N. \& MATSUOKA, K. Taxionomia e sistemática do gênero Phytophthora. Revisão Anual de Patologia de Plantas 4:297328. 1996.

LUZ, E.D.M.N., BEZERRA, J.L., RESENDE, M.L.V. \& OLIVEIRA, M.L. Cacau (Theobroma cacao L.) Controle de doenças. In:Ribeiro do Vale, F.X. \& Zambolim, L. (Eds.). Controle de doenças de plantas - grandes culturas. Viçosa, UFV, 2v. 1997. pp.617-622.

NEWHOOK, F.J., WATERHOUSE, G.M. \& STAMPS, D.J. Tabular key to the species of Phytophthora de Bary. Kew, Commonwealth Mycological Institute. Mycological Papers 143. 1978.

PANABIERES, F., MARAIS, A., TRENTIN, F., BONNET, P. \& 
Uso de marcadores RAPD na classificação de isolados de Phytophthora...

RICCI, P. Repetitive DNA polymorphism analysis as a tool for identifying Phytophthora species. Phytopathology 79:1105-1109. 1989.

SACKEY, S.T., AKROFI, A.Y., ASANTE APPIAH, A. \& OPOKU, I.Y. Phytophthora species differentiation by analysis of randomly amplified polymorphic DNAs. Proceeding of the $12^{\text {th }}$ International Cocoa Research Conference. Salvador, 1996. 1999. pp.107-112.

STAMPS, D.J., WATERHOUSE, G.M., NEWHOOK, F.J. \& HALL, G.S. Revised tabular key to the genus Phytophthora. Wallingford,
CAB International. Mycological Papers 162. 1990.

WATERHOUSE, G.M. Key to the species of Phytophthora de Bary. Kew, Commonwealth Mycological Institute. 80 p. Mycological Papers 92. 1963.

WATERHOUSE, G.M., NEWHOOK, F.J. \& STAMPS, D.J. Present criteria for classification of Phytophthora In: Erwin, D.C., BartnicGarcia, S. \& Tsao P.H. (Eds.) Phytophthora, its biology, taxonomy, ecology and pathology. St. Paul, Minnesota, American Phytopathological Society. pp.139-147. 1983. 